\title{
Strengthening of three-leaf stone masonry walls: an experimental research
}

\author{
D.V. Oliveira ${ }^{1}$, R.A. Silva ${ }^{2}$, E. Garbin ${ }^{3}$, P.B. Lourenço ${ }^{4}$
}

\begin{abstract}
The paper summarizes the results of an experimental research carried out on three-leaf masonry walls of typical granite stone constructions from the North of Portugal. The research aimed at studying the behaviour under compression of this wall typology, as well as the improvements introduced by common strengthening techniques applied for the structural rehabilitation of masonry heritage buildings. Ten masonry specimens were tested, plain or strengthened by transversal tying of the external leaves, with GFRP bars, or/and by injection of the inner leaf, with a lime-based grout. The results obtained showed that these strengthening techniques were successful in increasing the compressive strength of the walls and in improving their behaviour under compressive loads.
\end{abstract}

Keywords: Three-leaf walls, granite masonry, grout injection, transversal tying

${ }^{1} \mathrm{PhD}$, Associate Professor, ISISE, University of Minho, Department of Civil Engineering, Azurém, P-4800-058 Guimarães, Portugal. Phone: +351 253510 247, fax: +351 253510 217, email: danvco@ civil.uminho.pt

${ }^{2} \mathrm{PhD}$ student, ISISE, University of Minho, Department of Civil Engineering, Azurém, P-4800-058 Guimarães, Portugal. Phone: +351 253510 200, fax: +351 253510 217, email: ruisilva@civil.uminho.pt

${ }^{3} \mathrm{PhD}$, Research Assistant, University of Padova, Department of Structural and Transportation Engineering, Padova 35131, Italy. Phone: +39 049827 5631, fax: +39 049827 5631, email: garbin@dic.unipd.it

${ }^{4} \mathrm{PhD}$, Professor, ISISE, University of Minho, Department of Civil Engineering, Azurém, P-4800-058 Guimarães, Portugal. Phone: +351 253510 209, fax: +351 253510 217, email: pbl@ civil.uminho.pt 


\section{INTRODUCTION}

Multi-leaf masonry walls are quite common among masonry buildings in European historical centres and among important worldwide monuments. Three-leaf walls are composed by two external leaves of brickwork or stonework and by an inner leaf (or core). The core is usually made of rubble masonry or/and of very weak infill materials, such as earth or loose material. This leaf is, generally, characterized by a large percentage of voids and by low mechanical properties (Binda et al. 1999).

The lack or loss of bond between the different leaves is a typical problem associated with these traditional walls. This is often responsible for the formation of brittle collapse mechanisms that consist on the detachment of the external leaves and on their out-of-plane collapse, when the wall is submitted to excessive compressive or shear-compressive loadings (Anzani et al. 2004, Valluzzi et al. 2004, Binda et al. 2006, Mazzon et al. 2009). Indeed, the degradation of the bond between leaves is a natural process, which results from the ageing process of the materials or/and from the damaging effect of the loads. As a consequence, the overall bearing capacity of the walls is reduced with time, whereas the slenderness of the walls increases and the leaves exhibit a mechanical behaviour that is less dependent on each other (Vintzileou and Miltiadou 2008). Moreover, the different mechanical properties of the leaves also contribute to the brittleness of the compressive behaviour of these walls, by resulting on a non-uniform load distribution that promotes the out-of-plane collapse of the external leaves (Roque 2002; Valluzzi 2007) or/and damage by creep (Reda Taha and Shrive 2006).

Despite that, the cultural importance and historical value of many of the buildings that were built resorting to this masonry typology demand the development and practice of conservation and repair solutions, in order to stop their continuous degradation. Moreover, structural interventions are often required for improving the structural safety of these building, in order to adapt them to actual needs and keep them in use (Plevoets and Van Cleempoel 2009). Intervention on this kind of buildings requires a multidisciplinary approach to be followed (ICOMOS 2001), which might turn it into a rather complex process, where both image and substance of the historical construction should be preserved (Langenbach 1994). According to ICOMOS (2001), an intervention on a historical building should be limited to the minimum required to accomplish the objectives proposed. In addition, it has to be reversible in order to allow its easy removal without damaging the existent construction. This last requirement is, however, the hardest to be accomplished, since there is hardly any truly reversible intervention technique. Instead, one should look at the level of reversibility of the solution in order to make a decision. 
When dealing with such kind of interventions, the decision on the repairing/strengthening materials is a key issue. These materials must respect certain requirements, such as chemical and physico-mechanical compatibility with the original materials, in order to assure the efficiency and durability of the intervention and construction (Modena 1997, ICOMOS 2001, Binda 2006). Moreover, this decision assumes greater importance if the intervention technique is unlikely to be reversible.

Repointing or deep repointing, transversal tying of the external leaves and grout injection are, currently, among the intervention techniques preferred by the conservationists for strengthening and consolidating threeleaf masonry walls. Part of the success of these techniques can be attributed to their small aesthetical impact. Thus, research and developments were made on these techniques during the last years, whose main focus was the development of compatible materials. Nevertheless, the knowledge generated on the mechanical behaviour of three-leaf masonry walls and on the improvement provided by these techniques is still limited (Mazzon 2010).

The mechanical behaviour of ten three-leaf walls of granite masonry under compression is analysed and discussed in the paper, which involved the construction and testing of several masonry specimens representative of multi-leaf masonry of the North of Portugal. Some of the specimens were strengthened by transversal tying with GFRP bars of the external leaves or/and grout injection of the inner leaf. This experimental research aimed at characterizing the compressive behaviour of this specific wall typology and at evaluating the improvement provided by the mentioned popular strengthening techniques. Furthermore the work provides an experimental basis for future validation of numerical tools suitable for capturing and estimating the mechanical behaviour of this wall typology, see e.g. Lourenço and Pina-Henriques (2006) and Pina-Henriques and Lourenço (2006) for applications of micro-modelling and meso-modelling to masonry under compression.

\section{SHORT OVERVIEW ON THE STRENGTHENING OF THREE-LEAF STONE MASONRY WALLS}

As referred to previously, the most popular strengthening techniques for three-leaf masonry walls are repointing or deep repointing, transversal tying of the external leaves and grout injection. A short description on these techniques will be given hereafter, with special focus on the grout injection. Moreover, reference will be made to recent research dealing with the compressive behaviour of three-leaf walls of stone masonry, and with the effect of these techniques on the mechanical behaviour of this wall typology.

The repointing or deep repointing technique consists in removing part of the old mortar in the joints, which is then replaced by a new mortar of improved properties and durability (Valluzzi et al. 2004). This technique is 
greatly interesting for the case of brick masonry submitted to high sustained loads. The insertion of steel or Fibre Reinforced Polymer (FRP) bars along the bed joints allows to increase the tensile strength and to control the increase of horizontal deformations of masonry. Therefore, it constitutes a good solution to stop or counteract the progression of damage caused by creep phenomena (Valluzzi et al. 2005, Garbin et al. 2009).

The transversal tying of the external leaves aims at promoting or improving the bond between leaves by directly connecting them. Thus, it allows to reduce the brittleness associated with the traditional collapse mechanism, as well as limiting the transversal deformation of the wall (Valluzzi et al. 2004). For this purpose, stainless steel or FRP bars can be used. The bars are inserted into holes drilled through the thickness of the wall, which are then connected through anchoring devices or simply locally injected, which relies on the friction and adhesion between the bar and the grout. In this last case, FRP threaded bars or sand-coated bars should be preferred for improved friction (Oliveira et al. 2006).

Grout injection of the inner leaf is probably the most used technique for consolidating and strengthening three-leaf masonry walls, since it is a technique of simple application and it has reliable results. Nevertheless, the success of this intervention depends on the network of voids of the inner leaf, which must allow the grout to penetrate and to reach most voids and gaps between leaves. Thereby, walls with low percentage of voids (less than 4\%) seem unsuitable to be injected (Binda et al. 2006b). The injection of the core usually results on substantial improvement of its mechanical behaviour and on the improvement of the bond between leaves, which are then responsible for improving the global behaviour of the wall (Vintzileou and Miltiadou 2008). In addition, the injection of high-fluidity grouts can also repair cracks lying on external leaves.

Several kinds of grouts can be used for injecting masonry (e.g.: cement, lime, earth or resins based grouts), but nowadays the trend is to use binary or ternary grouts that present lime and pozzolan as the base binder and that incorporate limited cement content, which seems required for developing the initial strength (Toumbakari 2002, Vintzileou and Miltiadou 2008). The composition of these grouts is more similar to that of historic mortars, therefore they are expected to be more compatible with historical masonry. Moreover, their low content of cement reduces the risk of durability problems, such as the formation of ettringite after hardening of the grout (Toumbakari 2002). Also natural hydraulic lime gouts, with no cement added, have been used to further ensure durability and compatibility with historical original materials (Valluzzi et al. 2004).

During the last few years, some experimental research has been carried out on the compressive behaviour of three-leaf walls of stone masonry and on possible strengthening techniques. For example, Vintezileou and Tassios (1995) tested under compression eight three-leaf wallets of limestone masonry and lime/cement mortar. 
Before testing, two wallets were strengthened through injection of a high strength or medium strength grout (with a compressive strength value of $30 \mathrm{~N} / \mathrm{mm}^{2}$ and $13 \mathrm{~N} / \mathrm{mm}^{2}$, respectively), being both based on ordinary Portland Cement (OPC). The same grouts were used to repair four of the six wallets tested unstrengthened, which were retested after. These authors provided the following main remarks: (i) the unstrengthened wallets experienced early separation of the external leaves, which rapidly lead to the disintegration of the wallet due to second-order effects; (ii) the compressive strength of the wallets after being repaired was improved by $50 \%$ to $200 \%$ in relation to the initial strength; (iii) the compressive stiffness after repairing increased in most wallets; (iv) the homogenization effect introduced by the grout injection allowed the three-leaf wallets to behave almost as single-leaf.

Toumbakari (2002) tested under compression four three-leaf walls of limestone masonry with joints of lime/cement mortar. Like in the previous research, grout injection was the only studied repair/strengthening technique. Two ternary grouts (obtained from different blends of lime hydrate, Rheinisch trass, silica fume and OPC) and one OPC based grout (reference grout) were selected. The ternary grouts were low strength (compressive strength at 90 days of $9.0 \mathrm{~N} / \mathrm{mm}^{2}$ and of $7.3 \mathrm{~N} / \mathrm{mm}^{2}$ ), while the OPC grout was high strength (compressive strength at 90 days of $19.5 \mathrm{~N} / \mathrm{mm}^{2}$ ). From this research, Toumbakari (2002) remarked the following conclusions: (i) the collapse mechanism of the unstrengthened walls was consequence of the separation of the external leaves from the core; (ii) the compressive strength of the walls clearly increased after being injected, while the stiffness only increased for the walls repaired with the strongest grouts; (iii) the failure mode of the injected walls was similar to that before injection, however the transversal deformations (out-ofplane) were drastically reduced; (iv) the mechanical properties of the selected grouts seemed to have no influence on the effectiveness of the injection.

Valluzzi at al. (2004) tested under compression seventeen three-leaf walls of limestone masonry with rubble masonry external leaves. The walls were tested unstrengthened or strengthened resorting to natural hydraulic lime grout injection, transversal tying, repointing or combination of these techniques. After testing, some of the unstrengthened walls were also repaired by resorting to these techniques, and subsequently retested. Two low strength grouts were used on the injection interventions (compressive strength at 28 days of $5.1 \mathrm{~N} / \mathrm{mm}^{2}$ and of $3.2 \mathrm{~N} / \mathrm{mm}^{2}$ ), while a natural hydraulic lime mortar was used for repointing (compressive strength at 28 days of $1.72 \mathrm{~N} / \mathrm{mm}^{2}$ ). The transversal tying technique was applied by resorting to stainless steel rebars or threaded bars (four bars per $\mathrm{m}^{2}$ of wall) that were anchored by bending the rods from outside into a previously excavated mortar joint or through a system of washers and nuts, respectively. The main relevant remarks derived from this 
research were: (i) the failure of unstrengthened walls was consequence of the high transversal deformation of the external leaves, which caused their out-of-plane collapse; (ii) the injection was shown to be the most efficient technique, since it promoted the improvement of the compressive strength in $40 \%$ (average) and of the stiffness in $30 \%$ (average), as well it promoted the bond between leaves that resulted on a less brittle failure mode; (iii) the other techniques revealed their effectiveness mostly in terms of reduction of deformations; (iv) the best behaviour performance was achieved by combined techniques, especially when injection was involved. Recently, by using the same limestone masonry and the lime grout with best performance, an experimental research regarding the influence of the injection technique on the dynamic behaviour of stone masonry dwellings in unreinforced, repaired and strengthened conditions was carried out (Mazzon et al. 2009, Mazzon 2010). Two identical two-story models, with wooden floors, were built in reduced scale of 2:3 and tested on a shaking table. The first unreinforced model was preliminary damaged and then repaired using natural hydraulic lime based grout injection before the final test; while the second model was strengthened before testing. The main outcomes of this research were: (i) the injection technique can significantly reduce the detachment of external leaf and outof-plane collapse; (ii) both injected models could resist a higher peak ground acceleration than the unreinforced model, with an increment of 30 and $50 \%$ for repairing and strengthening interventions, respectively; (iii) the injection technique reduces the crack pattern at failure and does not practically modify the dynamic characteristics (initial frequencies and modal deformations) of original structure in both cases.

The differences between the aforementioned researches are substantial, since different materials, geometries, masonry fabric and testing procedures were used and adjusted to the specific masonry typology and to the available testing conditions. This compromises any attempt in comparing directly the results of these researches. Nevertheless, all authors agreed on the failure mode of unstrengthened three-leaf walls of stone masonry and on the improvement provided by the injection technique. Moreover, the good efficiency of low strength grouts, when compared with that of high strength, encourages the use of ternary and binary grouts in the conservation of historical masonry constructions.

\section{EXPERIMENTAL PROGRAM}

The experimental research presented in this paper involved the construction and testing of three sets of three-leaf walls of granite masonry. Due to laboratory constraints, sets were built at different dates, being the first fully dedicated to the testing of unstrengthened walls. The second set was dedicated to the testing of walls strengthened by transversal tying of the external leaves, while the third was dedicated to the testing of walls 
strengthened by grout injection. In the third set, a wall was additionally strengthened simultaneously by transversal tying and grout injection. Since the limited storage area available forced a phased construction of the walls, the second and third sets of walls included the testing of reference unstrengthened walls in order to detect possible constructive differences between sets. Still, note that the same workers (specialized in conservation) were used to build all specimens. The test matrix for the three-leaf walls is presented in Table 1. The first number in the label recalls the set number, the letter "W" stands for test on wall, and the last number indicate the test number.

\subsection{Materials}

\subsubsection{Stone}

Granite obtained from a quarry in Mondim de Basto, North of Portugal, was used for building the walls. Stones of irregular size and shape were used in the masonry of the external leaves, while granite splinters were used as filling material of the inner leaf. The mechanical characterization of the granite was carried out on six cylindrical specimens (dimensions of $\varnothing 100 \times 200 \mathrm{~mm}^{2}$ ) that were tested under compression. The obtained average compressive strength, Young's modulus and Poisson's ratio were $52.2 \mathrm{~N} / \mathrm{mm}^{2}, 20.6 \times 10^{3} \mathrm{~N} / \mathrm{mm}^{2}$ and 0.24 , respectively. A more detailed characterization of this granite can be found in Vasconcelos et al. (2009).

\subsubsection{Mortar}

The composition of the mortar used for building the walls was based on references about historical mortars (Baronio and Binda 1997, Baronio et al. 2000, Binda et al. 2000, Charola and Henriques 2000, Klrca 2004, Teutonico et al. 2000, Toumbakari et al. 2000). A low strength pozzolanic mortar of hydrated lime and metakaolin was defined for this purpose. The composition of the binder was chosen to be $25 \%$ of hydrated lime and $75 \%$ of metakaolin (in weight), in order to promote hardening exclusively by hydration, and consequently, to grant that the mortar would achieve a strength close to the maximum in short-term, reducing the curing time of the walls. The adopted binder/sand ratio was 1:3, while the water/binder ratio was 0.8 (all ratios in weight). Furthermore, a pozzolanic dryer (10\% of the binder weight) was added in order to improve the workability. The compressive strength of the mortar was assessed on cubic specimens of $50 \times 50 \times 50 \mathrm{~mm}^{3}$ sampled during the construction of the walls sets. Similar curing conditions to that of the walls were adopted for the mortar specimens, which were tested under compression at the ages of 7, 28 and 90 days. The average compressive strengths computed for the aforementioned ages were $0.5 \mathrm{~N} / \mathrm{mm}^{2}, 2.9 \mathrm{~N} / \mathrm{mm}^{2}$ and $2.2 \mathrm{~N} / \mathrm{mm}^{2}$, respectively. 
This composition resulted from a study carried out with the aim to investigate the influence of the mortar composition on the time-evolution of the compressive strength. This experimental study involved 15 different mortar compositions, which differ on the binder composition and on the amount of added pozzolanic dryer (see also Table 2). The results, using the specified specimens and age, are graphically represented in Fig. 1, being the compressive strength of each mixture computed as the average of three specimens. At a first glance, the graphs show that the mortars incorporating a percentage of metakaolin above $50 \%$ present a strength decrease after 28 days, instead of the expected positive evolution due to the progression of hydration or carbonation. The causes associated with this behaviour need to be further assessed. Cizer (2009) has associated this unexpected strength evolution with the formation of strätlingite in lime hydrate/metakaolin mortars, as a consequence of the destruction of the C-S-H and C-A-H phases, by their interaction with the alumina and silica of the unreacted metakaolin, respectively (Ding et al. 1995). A high percentage of metakaolin should be avoided in practical applications, to prevent the destruction of the main hydrated phases contributing to the strength of the mortar. According to Cizer (2009), unreacted metakaolin can be avoided by keeping the percentage of this pozzolana below $50 \%$. This statement is in agreement with the results provided by the current composition study, since the strength showed no decrease after 28 days for the mortars prepared with $50 \%$ of lime and $50 \%$ of metakaolin. In fact, these mortars seem to show strength stability after 28 days, which can indicate that almost all lime was consumed in the pozzolanic reaction, while the unreacted metakaolin was kept to a minimum. On the other hand, hardening occurring partially by carbonation was evident in mortars with percentage of metakaolin below $50 \%$ due to their substantial strength increase after 28 days. The contribution of the pozzolanic dryer to the increase in strength is evident as well, as this material is constituted mainly by calcium oxide that acts as extra binder (Silva 2008). For the purpose of keeping the strength values approximately constant in the period 28-90 days, a percentage around $50 \%$ of metakaolin seems adequate. The selected mortar composition incorporated more metakaolin as an attempt to obtain a more eco-efficient material.

\subsection{Walls geometry and construction}

The wall specimens represent half-scale models of original walls of the typology being studied, and were built with the dimensions shown in Fig. 2a, which are similar to dimensions adopted in previous experimental research, see Table 3. The two external leaves were of irregular granite masonry (see Fig. 2b), and the core between them was filled by pouring, without compaction, alternate layers of granite splinters and mortar (see Fig. 2c). This procedure was originally followed by Vintzileou and Tassios (1995), whose aim was to obtain a percentage of voids in the inner leaf between $30 \%$ and $40 \%$. During the construction, no mechanical connections 
(e.g. keystones) were introduced in order to simulate the least favourable interface between leaves. After construction, the wall specimens were kept covered by a wet blanket during two weeks in order to avoid shrinkage due to fast drying, and to supply the moisture required for hydration of the mortar.

\subsection{Specimens from the leaves}

The compressive strength of the external and inner leaves was assessed on representative specimens prepared during the construction of each set of walls, which were subsequently tested under compression (Silva 2008). The external leaf specimens consisted on three stones and two bed joints (see Fig. 3a), while the inner leaf specimens were prepared resorting to common cylindrical moulds $\left(\varnothing 150 \times 300 \mathrm{~mm}^{2}\right)$, which were filled by alternate layers of granite splinters and mortar in a similar procedure to that used in the construction of the walls (see Fig. 3b). The curing condition of these specimens was the same as for the walls. In addition, the compressive strength of the inner leaf after injection was assessed through compressive tests on prismatic specimens (average dimensions of $80 \times 80 \times 160 \mathrm{~mm}^{3}$ ) sampled from undamaged portions of the inner leaf removed from the injected walls after being tested (see Fig. 3c).

\subsection{Strengthening of the walls}

GFRP rods of $10 \mathrm{~mm}$ diameter and sand-coated surface were employed in the strengthening by transversal tying. The tensile strength of the rods was provided by the supplier and was of about $760 \mathrm{~N} / \mathrm{mm}^{2}$, which is more than sufficient to absorb elastically the low stresses generated during the testing of the walls. This technique consisted in installing two ties per wall (see Fig. 4a), whose anchoring was exclusively based on the bond behaviour granted by a hydraulic commercial grout developed for historical masonry (Mape-Antique I), injected locally by gravity, see Fig. 4 b and Fig. 4c. Cubic specimens $\left(50 \times 50 \times 50 \mathrm{~mm}^{3}\right)$ sampled from the grout were tested under compression and direct tension, reaching the values of $17.6 \mathrm{~N} / \mathrm{mm}^{2}$ (at 43 days) and $0.3 \mathrm{~N} / \mathrm{mm}^{2}$ (at 60 days), respectively. The same commercial grout was used in the strengthening by grout injection of the inner leaf. In this case, only the compressive strength of the grout was controlled, and was found to be $13.7 \mathrm{~N} / \mathrm{mm}^{2}$ (at 60 days). Due to the reduced thickness of the inner leaf, the injection tubes (10 $\mathrm{mm}$ diameter) were installed on just one of the faces of the walls (see Fig. 5a), whose holes were drilled at the joints and followed a quincunx arrangement. This resulted on a vertical spacing of the tubes between $100 \mathrm{~mm}$ and $200 \mathrm{~mm}$, while the horizontal spacing was between $250 \mathrm{~mm}$ and $300 \mathrm{~mm}$. The transversal faces of the walls were sealed by application of a layer of polyurethane foam, see Fig. $5 b$, which is a resilient material and thereby it does not contribute to the stiffness of the walls. In the day before injection, water was injected in order to wet the material at the core, and 
thus to avoid excessive water adsorption that would hinder the injection. A pressure pot (see Fig. 5c) was used for injecting the walls at low pressure (around $0.1 \mathrm{~N} / \mathrm{mm}^{2}$ ), starting from the bottom up to the top of the wall. The injection of the tyings of wall 3W4 was carried out simultaneously with the integral injection of the inner leaf. During the strengthening interventions, the walls were slightly compressed along the vertical direction, between two steel plates in order to simulate real conditions and to minimize any possible damage caused by drilling or injection pressure.

On average, $28.5 \mathrm{dm}^{3}$ of grout were injected per wall (assuming that the grout leakage was minimum), corresponding to a volume of $15 \%$ of the total volume specified for the walls or to an average inner leaf void percentage of about $33 \%$. These values are in agreement with the initially assumed percentage of voids.

\subsection{Test setup and procedure}

All wall specimens were tested under monotonic compression using a $2 \mathrm{MN}$ closed-loop servo-controlled testing machine, see Fig. 6a. The tests were performed under displacement control at constant rate of $3 \mu \mathrm{m} / \mathrm{s}$, being stopped during the softening branch just before the failing of specimens. In the case of the walls strengthened by injection, the external leaves were carefully dismantled after testing, in order to check the quality of the strengthening procedure. During the tests, the displacements in the walls were measured by means of linear variable displacement transducers (LVDTs) disposed according to Fig. 6b. The LVDT layout in the walls aimed at measuring vertical, horizontal and transversal displacements directly on the walls, in order to compute elastic mechanical parameters. One external LVDT was used to measure the displacement between the plates of the testing machine and to control the tests.

\section{RESULTS AND DISCUSSION}

\subsection{Specimens from the leaves}

The results of the compressive tests carried out on the specimens of the leaves are summarized in Table 4. It should be remarked that the compressive strength of the external leaves is around 30 times greater than that of the inner leaf. Moreover, the grout injection increased about 14 times the initial compressive strength of the inner leaf, whose homogenization after injection is indicated by a remarkably lower value of the coefficient of variation. 


\subsection{Unstrengthened walls}

Table 5 summarizes the results of the compressive tests carried out on the four unstrengthened walls (within the three sets) in terms of compressive strength $\left(f_{c, W}\right)$, vertical strain $\left(\varepsilon_{v, p}\right)$ and horizontal strain $\left(\varepsilon_{h, p}\right)$ at peak load, Young's modulus computed in the [0\%-20\%] stress range $\left(E_{0}\right)$ and in the [30\%-60\%] stress range $\left(E_{30-60}\right)$. On average terms, the compressive strength of the unstrengthened walls is around $22 \%$ of that of the external leaf specimens and about $4 \%$ of that of the granite stone. This result is not surprising and highlights the need in consider always representative specimens instead of just stone samples. The scattering found in all computed parameters is large, especially in the case of the deformability parameters. This is an expected consequence of workmanship, variability of the raw materials and heterogeneity of the masonry.

As aforementioned, the computation of the Young's modulus was done in two intervals of stress by linear fitting, and assessment of the degradation of this parameter with increasing stress levels is possible. On average, the drop between Young's modulus in the [0\%-20\%] and [30\%-60\%] stress range was of about $44 \%$, which is evident in the stress - strain curves illustrated in Fig. 7. Two distinct stiffness degradation zones are identified, whose transition can be associated with the detachment of the external leaves, which seemed to take place between $25 \%$ and $35 \%$ of the compressive strength of the walls. However, in wall $1 \mathrm{~W} 2$ this event seems to happen at stress levels substantially higher. This conflicting behaviour may be attributed to construction issues, which may have conferred this wall an improved connection between leaves.

The failure mode observed in the unstrengthened walls consisted in the out-of-plane rotation of the external leaves, as reported by other researchers (Vintezileou and Tassios 1995; Toumbakari 2002; Valluzzi et al. 2004). Thus, the out-of-plane rotation of the external leaves was evaluated in terms of a dimensionless parameter $\lambda$, defined as the average of the four measurements:

$$
\lambda=\frac{\sum_{i=1}^{4} \frac{\Delta l_{i}}{h_{i}}}{4}
$$

where $\Delta l_{i}$ is the displacement recorded by the transversal LVDT $i$ and $h_{i}$ is the vertical distance between the LVDT $i$ and the top or the bottom plate (the closest one). The relation between $\lambda$ and the compressive stress of the unstrengthened walls is given in Fig. 8, which confirms the remark done about the early separation of the leaves.

The observation of the crack pattern on the unstrengthened walls after testing, as illustrated in Fig. 9, allowed identifying the formation of a collapse mechanism in each of the external leaves. This mechanism 
consisted in the formation of three horizontal cracks along the bed joints leading to the out-of-plane rotation caused by second-order effects. Two of these horizontal cracks are formed close to the machine plates and they are not visible on the facade, since the cracks are developed inside the outer leaf. On the other hand, a third horizontal major crack is identified at a bed joint near the middle-height of the wall. Further cracking seems to concentrate around the middle-height and it is mainly constituted by vertical cracks around the masonry stones. Therefore, the strength of the external leaves was not fully mobilized, and the collapse was rather caused by instability phenomena that resulted on the separation of the leaves.

\subsection{Walls strengthened by transversal tying}

The results concerning walls strengthened by transversal tying are summarized in Table 6. On average, the presence of the tyings improved the compressive strength in about 55\%. However, both computed average Young's modulus were lower than those of the unstrengthened walls. This is explained by factors associated with construction differences between each set of walls, which affected mainly the deformability parameters. However, if these parameters of the strengthened walls are compared with those of the reference unstrengthened walls of each set, it is possible to observe that $E_{0}$ increased $13 \%$, while $E_{30-60}$ was $6 \%$ lower. Moreover, the drop between these two parameters is comparable to that of the reference walls. Thus, the impact of this technique on the stiffness seems to be almost irrelevant. However, the stress - strain curves of Fig. 10 show smooth and continuous stiffness degradation, instead of a sudden break, as it was observed for the unstrengthened walls. This means that the tyings were able to control the abrupt separation between leaves, as it can be seen in Fig. 11. It should be noted that the tyings have a local effect, thereby the displacement between leaves, measured at the edges of the walls, is greater than if measured at the tyings. This difference becomes even greater as the wall approaches stress levels close to the peak load, as no failure was noticed in the tyings before this point.

The crack pattern of the wall 2W4 at near-collapse condition is shown in Fig. 12, and it is mainly constituted by cracks of vertical orientation. It was not possible to detect relevant horizontal cracks in correspondence with the formation of the out-of-plane mechanism already discussed. Since the presence of the tyings prevented or delayed the formation of this mechanism, the collapse happened due to localized instability related to the detachment of portions of the external leaves that were out of the influence area of the tyings.

\subsection{Walls strengthened by grout injection}

The main results regarding injected walls are summarized in Table 7. The grout injection improved remarkably the strength of the walls, which show an average increase of about $80 \%$ with respect to the unstrengthened walls. 
The computed Young's modulus increased, in relation to the reference wall, about $16 \%$ and $1 \%$ for $E_{0}$ and $E_{30-60}$, respectively. This is explained by the incorporation of the grout in the void network of the inner leaf, which increases its stiffness. A slight increase, as the observed one, is preferable in real interventions in order not to compromise the mechanical compatibility. Additionally, the grout injection promoted a less pronounced dropping between $E_{0}$ and $E_{30-60}$, which was of about $32 \%$.

Vintzileou (2007) proposed the following equation to estimate the compressive strength of an injected wall $f_{c w, i}$

$$
f_{c w, i}=f_{c w, 0}\left(1+\frac{V_{i}}{V_{w}} \frac{f_{c i i l}}{f_{c w, 0}}\right)
$$

where $f_{c w, 0}$ is the average compressive strength of the unstrengthened walls $\left(2.0 \mathrm{~N} / \mathrm{mm}^{2}\right), f_{c i i l}$ is the average compressive strength of the specimens of the injected inner leaves $\left(4.1 \mathrm{~N} / \mathrm{mm}^{2}\right)$, and $V_{i}$ and $V_{w}$ are the volumes of the inner leaf and of the wall, respectively. For the injected walls discussed in this paper $f_{c w, i}$ was estimated to be about $3.6 \mathrm{~N} / \mathrm{mm}^{2}$ and $4 \mathrm{~N} / \mathrm{mm}^{2}$ for the walls $3 \mathrm{~W} 2$ and $3 \mathrm{~W} 3$, respectively. The $f_{c w, i}$ value estimated for wall $3 \mathrm{~W} 2$ is slightly lower than the compressive strength obtained from the test, while for wall $3 \mathrm{~W} 3$ is higher. However, Eq. (2) seems to give a good approximation of the compressive strength of the injected walls, even if it does not account for second-order effects, different deformability properties of the leaves, and bond and interaction between leaves (Vintzileou and Miltiadou 2008).

Fig. 13 shows the stress-strain curves of the injected walls, where continuous stiffness degradation can be observed, similar to the walls strengthened by transversal tying. However, a slight shift of the $3 \mathrm{~W} 3$ wall curve can be observed at a stress of about $0.8 \mathrm{~N} / \mathrm{mm}^{2}$, which was somehow unexpected. This behaviour is associated with a zone of the inner leaf not completely injected, detected during the dismantling of the wall. Consequently, a premature local detachment of the external leaf took place, which is evidenced by the $\lambda$ parameter curve of Fig. 14. This figure also shows that the separation of the leaves started later than in the walls strengthened by transversal tying. However, the sudden increase of the separation rate of the leaves of the injected walls at an early stage seems to reveal a more brittle behaviour. Moreover, the injection seems to be not as efficient as the strengthening by transversal tying in controlling the separation of the leaves next to the peak load. These differences in behaviour are explained by the nature of bond between leaves. On one hand, the grout provides a bond that is distributed along the surface, thereby it greatly contributes for maintaining the leaves together up to its failure. Upon bond failure and as brittle cracks are formed at the leaves interfaces, the grout starts loosing quickly its capacity in maintaining the leaves together. On the other hand, the tyings provide a local bond, which allows the separation of the leaves at zones that are out of their influence. However, the tyings are unlikely to fail 
before the peak stress, and even if this is the case, there is a remaining residual friction that makes the separation less brittle and more progressive.

The near-collapse crack pattern of wall $3 \mathrm{~W} 3$ is presented in Fig. 15, and it is composed mainly by vertical cracks. The cracks are dispersed all over the area of the facades, indicating that the external leaves were greatly mobilized and had a great contribution to the response of the wall. Additionally, some horizontal cracks appeared at the end of the test, indicating the incipient onset of a possible out-of-plane mechanism. During the dismantling of this wall, important vertical cracks developed at the inner leaf were also detected, which highlights the relevant contribution of this leaf on the response of the wall.

The failure of the injected walls was mainly due to localized stone cracking and instability, which were accompanied by the detachment of stones or parts of the external leaves. Nevertheless, it can be concluded that the strengthening by injection prevented the full detachment of the leaves, whereas the vertical cracks at the interface between leaves were not formed in all its extension.

\subsection{Wall strengthened by transversal tying and grout injection}

Table 8 summarizes the results of wall 3W4, strengthened simultaneously by transversal tying and injection. Since only one wall was tested using this strengthening intervention, the comments given hereinafter require further experimental verification. This strengthening intervention led to a compressive strength similar to that of the injected walls, and it was $90 \%$ higher than that of the unstrengthened walls. Regarding the computed Young's modulus, there was an increase relatively to the reference unstrengthened wall of about $104 \%$ and $37 \%$ for $E_{0}$ and $E_{30-60}$, respectively. This high increase was not expected, nevertheless a single test does not allow to clarify this remark.

The stress-strain curve of wall 3W4 is depicted in Fig. 16, with smooth and continuous stiffness degradation, similar to that of the injected walls. This feature is further confirmed by Fig. 17, where the evolution of the $\lambda$ parameter seems to indicate that the simultaneous use of both strengthening techniques is beneficial in the sense that a better global structural behaviour is achieved, namely in terms of stiffness degradation and control of the out-of-plane deformation of the external leaves.

The near-collapse crack pattern of wall 3W4 is illustrated in Fig. 18, where the cracks are mainly vertical and dispersed all over the facade. Moreover, some cracks crossed the stones of the external leaves, indicating its great contribution to the response of the walls. The collapse of the wall was due to instability of stones located at the edge of the wall, distant from the relatively localized effect of the tyings. During the dismantling of the wall, 
long vertical cracks crossing the entire inner leaf were also observed, showing again the great contribution of the injected core to the wall response.

\section{CONCLUSIONS}

From the experiments carried out and discussed in this paper, the following main conclusions can be derived:

- The unstrengthened walls showed two distinct zones of stiffness degradation related to the early and brittle detachment of the external leaves. This resulted on a collapse mechanism governed by the out-ofplane rotation of the external leaves, due to second-order effects;

- All the three strengthening techniques tested led to improvements of the compressive strength of the walls. The technique that allowed the highest improvement was the combination of injection and transversal tying, with a strength increase of about $90 \%$, followed by the injection technique, with $80 \%$ increase, and finally the transversal tying technique, with $55 \%$ increase;

- The strengthening caused also an increase of the initial stiffness of the walls, around $13 \%$ for walls strengthened by the transversal tying, $16 \%$ for the injected walls and $104 \%$ for the wall strengthened by combination of these techniques. With the exception of the last case, requiring further confirmation, these increases can be considered low to moderate, thereby these techniques seem to be mechanically compatible with this wall typology;

- The separation of the external leaves at stress levels close to the compressive strength was better controlled by transversal tying rather than by grout injection. Moreover, the brittle detachment of the leaves was reduced and the development of the typical collapse mechanism was avoided, when comparing with the unstrengthened walls. However, the tyings were ineffective to control the detachment of zones out of their influence area, which resulted in local failures responsible for the global failure of the wall;

- The grout injection promoted a greater contribution of the inner leaf to the response of the walls, due to the improvement of the mechanical properties of this leaf and of the improvement of the bond between leaves. In fact, the bond provided by the grout remarkably reduced the separation of the external leaves up to failure. Nevertheless, failure occurred in a brittle way, which subsequently resulted in an ineffective control of the leaves separation. Moreover, it was shown that it is important to control the quality of the injection, since the presence of non-injected voids has great influence on the behaviour of the walls; 
- The results obtained by combining transversal tying with grout injection seem to show that the benefits of both techniques applied separately were gathered;

- Although the transversal tying technique might have a visual impact in unplastered walls and become inapplicable in the case of presence of irremovable decorative elements, this technique has much less visual impact than a solution that requires the use of anchoring elements.

\section{ACKNOWLEDGEMENTS}

The authors would like to thank the technical staff of the Structural Laboratory of University of Minho for the help provided. Acknowledgements are also due to the companies Fradical, Mapei and Augusto de Oliveira Ferreira for providing raw materials and workmanship. Finally, the funding provided by the Portuguese Science and Technology Foundation, through the POCI/ECM/58987/2004 project, is gratefully acknowledged.

\section{REFERENCES}

Anzani A., Binda L., Fontana A., Pina Henriques J. (2004) An experimental investigation on multiple-leaf stone masonry, 13th International Brick and Block Masonry Conference, Amsterdam, 10 pp., (CD-ROM).

Baronio G., Binda L. (1997) Study of the pozzolanicity of some bricks and clays, Construction and Building Materials 11(1), pp. 41-46.

Baronio G., Binda L., Saisi A. (2000) Mechanical and Physical Behaviour of Lime Mortars Reproduced After the Characterization of Historic Mortar, In Historic Mortars: Characteristics and Tests: proceedings of a RILEM International Workshop, Paisley 1999, Bartos P.J.M., Groot C.J.W. and Hughes J.J. eds, pp. 307325.

Binda L. (2006) The difficult choice of materials used for the repair of brick and stone masonry walls, 1st International Conference on Restoration of Heritage Masonry Structures, Cairo, Egypt, (CD-ROM).

Binda L., Baronio G., Penazzi D., Palma M., Tiraboschi C. (1999) Characterization of stone masonry walls in seismic areas: data-base on the masonry sections and materials investigations (in Italian), L'ingegneria Sismica in Italia, $9^{\text {th }}$ National Conference, Turin, Italy, 14 pp., (CD-ROM).

Binda L., Baronio G., Tedeschi C. (2000) Experimental study on the mechanical role of thick mortar joints in reproduced byzantine masonry, In Historic Mortars: Characteristics and Tests: proceedings of a RILEM International Workshop, Paisley 1999, Bartos P. J. M., Groot C. J. W. and Hughes J. J. eds, pp. 227-247. 
Binda L., Pina-Henriques J.L., Anzani, A. Fontana, A. Lourenço P.B. (2006a) Understanding load-transfer mechanisms in multi-leaf masonry walls, Engineering Structures, 28 (8), pp. 1132-1148.

Binda L., Saisi A., Tedeschi C. (2006b) Compatibility of materials used for repair of masonry buildings: research and applications, In Fracture and Failure of Natural Building Stones: Applications in the Restoration of Ancient Monuments, Kourkoulis S.K. ed., Springer, Dordrecht, Netherlands, pp. 167-182.

Charola A.E., Henriques F.M.A. (2000) Hydraulicity in lime mortars revisited, In Historic Mortars: Characteristics and Tests: proceedings of a RILEM International Workshop, Paisley 1999, Bartos P.J.M., Groot C.J. W. and Hughes J.J. eds, pp. 95-104.

Cizer O. (2009) Competition between carbonation and hydration on the hardening of calcium hydroxide and calcium silicate binders, PhD Dissertation, Katholieke Universiteit Leuven, Belgium.

Ding J., Fu Y., Beaudoin J.J. (1995) Strätlingite Formation in High Alumina Cement-Silica Fume Systems: Significance of Sodium Ions, Cement and Concrete Research, 25(6), pp. 1311-1319.

Garbin E., Valluzzi M.R., Modena C. (2009) Testing and numerical modelling of the structural behaviour of brick masonry strengthened by the bed joints reinforcement technique, In Proc. $1^{\text {st }}$ WTA International PhD Symposium - Building materials and building technology to preserve the built heritage, Schueremans L. ed, October 8-9, Leuven, Belgium, pp. 489-516

ICOMOS (2001) Recommendations for the analysis, conservation and structural restoration of architectural heritage, International Scientific Committee for Analysis and Restoration of Structures of Architectural Heritage.

Klrca Ö. (2004) Ancient binding materials, mortars and concrete technology: History and Durability Aspects, 4th International Seminar on Structural Analysis of Historical Constructions, Italy, pp. 87-94.

Langenbach R. (1994) Architectural issues in the seismic rehabilitation of masonry buildings, US-Italy workshop on guidelines for seismic evaluation and rehabilitation of unreinforced masonry buildings. Technical report NCEER-94-0021.

Lourenço P.B., Pina-Henriques J.L., (2006) Masonry micro-modelling: a continuum approach in compression, Computers \& Structures, 84(29-30), pp. 1977-1989.

Mazzon N. (2010) Influence of grout injection on the dynamic behaviour of stone masonry buildings, PhD Dissertation, University of Padova, Italy. 
Mazzon N., Valluzzi M.R., Aoki T., Garbin E., De Canio G., Ranieri N., Modena C. (2009) Shaking table tests on two multi-leaf stone masonry buildings, 11th Canadian Masonry Symposium, Toronto, Ontario, May 31June 3, pp. 325-334

Modena C. (1997) Criteria for cautious repair of historic building. Evaluation and strengthening of existing masonry structures, Binda L. and Modena C., Ed. RILEM, pp. 25-42

Oliveira D.V., Lourenço P.B., Garbin E., Valluzzi M.R., Modena C. (2006) Experimental investigation on the structural behaviour and strengthening of three-leaf stone masonry walls, Structural Analysis of Historical Constructions, New Delhi, pp. 817-826.

Pina-Henriques J.L., Lourenço P.B., (2006) Masonry compression: a numerical investigation at the meso-level, Engineering Computations, 23(4), pp. 382-407.

Plevoets B. and Van Cleempoel K. (2009) Retail-reuse of historic buildings: developing guidelines for designer and conservators, In Proc. $1^{\text {st }}$ WTA International PhD Symposium - Building materials and building technology to preserve the built heritage, Schueremans L. ed, October 8-9, Leuven, Belgium, pp. 61-80.

Reda Taha M.M. and Shrive N.G. (2006) A Model of Damage and Creep Interaction in a Quasi-Brittle Composite Materials Under Axial Loading, Journal of Mechanics, 22(4), pp. 339-347

Roque J. (2002) Strengthening and structural rehabilitation of old masonry walls (in Portuguese), Msc Dissertation, University of Minho, Guimarães, Portugal. Available from www.civil.uminho.pt/masonry.

Silva R.A. (2008) Experimental characterization of ancient masonry: strengthening and long-term effects (in Portuguese), Msc Dissertation, University of Minho, Portugal. Available from www.civil.uminho.pt/masonry.

Teutonico J.M., Ashall G., Grrod E., Yates T. (2000) A comparative study of hydraulic lime-based mortars, In Historic Mortars: Characteristics and Tests: proceedings of a RILEM International Workshop, Paisley 1999, Bartos P.J.M., Groot C.J. W. and Hughes J.J. eds, pp. 339-349.

Toumbakari E.-E. (2002) Lime-pozzolan-cement grouts and their structural effects on composite masonry walls, PhD Dissertation, Katholieke Universiteit Leuven, Belgium.

Toumbakari E.-E., van Gemert D., Tassios T.P. (2000) Methodology for the design of injection grouts for consolidation of ancient masonry, In Historic Mortars: Characteristics and Tests: proceedings of a RILEM International Workshop, Paisley 1999, Bartos P.J.M., Groot C.J. W. and Hughes J.J. eds, pp. 395-405.

Vasconcelos G., Lourenço P.B., Alves C.A.S., Pamplona J. (2009) Compressive behavior of granite: Experimental approach, Journal of Materials in Civil Engineering, 21(9), pp. 502-511. 
Valluzzi M.R. (2007) On the vulnerability of historical masonry structures: analysis and mitigation, Materials and structures, 40(7), pp. 723-743.

Valluzzi M.R., Binda L., Modena C. (2005) Mechanical behaviour of historic masonry structures strengthened by bed joints structural repointing, Construction and Building Materials, 19(1), pp. 63-73.

Valluzzi M.R., da Porto F., Modena C. (2004) Behavior and modeling of strengthened three-leaf stone masonry walls, Materials and structures, 37(3), pp. 184-192.

Vintzileou E. (2007) Iniezione di miscela fluida in muratura a sacco: Risultati sperimentali e previsione delle caratteristiche meccaniche, Seminar CIAS Evoluzione nella sperimentazione per le costruzioni, pp. 191211.

Vintzileou E., Miltiadou-Fezans A. (2008) Mechanical properties of three-leaf stone masonry grouted with ternary or hydraulic lime-based grouts, Engineering Structures, 30(8), pp. 2265-2276.

Vintzileou E., Tassios T.P. (1995) Three-leaf stone masonry strengthened by injecting cement grouts, Journal of Structural Engineering, 121(5), pp. 848-856. 


\section{LIST OF TABLES CAPTIONS}

Table 1 - Experimental program on the wall-specimens.

Table 2 - Mortars tested in the composition study.

Table 3 - Geometry of wall specimens tested in previous research works.

Table 4 - Compressive strength of the specimens of the leaves (the coefficient of variation is indicated inside parentheses).

Table 5 - Summary of results of the unstrengthened walls.

Table 6 - Summary of results of the walls strengthened by transversal tying.

Table 7 - Summary of results of the walls strengthened by grout injection.

Table 8 - Summary of results of the wall strengthened by combination of transversal tying and grout injection. 
Table 1 - Experimental program on the wall-specimens.

\begin{tabular}{ccc}
\hline Wall label & Set & Strengthening technique \\
\hline $1 \mathrm{~W} 1$ & 1 & $\mathrm{U}$ \\
$1 \mathrm{~W} 2$ & 1 & $\mathrm{U}$ \\
$2 \mathrm{~W} 1$ & 2 & $\mathrm{U}$ \\
$2 \mathrm{~W} 2$ & 2 & $\mathrm{~T}$ \\
$2 \mathrm{~W} 3$ & 2 & $\mathrm{~T}$ \\
$2 \mathrm{~W} 4$ & 2 & $\mathrm{~T}$ \\
$3 \mathrm{~W} 1$ & 3 & $\mathrm{U}$ \\
$3 \mathrm{~W} 2$ & 3 & $\mathrm{I}$ \\
$3 \mathrm{~W} 3$ & 3 & $\mathrm{I}$ \\
$3 \mathrm{~W} 4$ & 3 & $\mathrm{~T}+\mathrm{I}$ \\
\hline U - Unstrengthened $/$ T-Transversal tying / I - Injection
\end{tabular}


Table 2 - Mortars tested in the composition study.

\begin{tabular}{|c|c|c|c|}
\hline \multirow{2}{*}{ Mortar } & \multicolumn{2}{|c|}{ Binder } & \multirow{2}{*}{$\begin{array}{l}\text { Pozzolanic } \\
\text { dryer }(\%)\end{array}$} \\
\hline & Lime $(\%)$ & Metakaolin (\%) & \\
\hline L0M100_12 & 0 & 100 & 12 \\
\hline L0M100_8 & 0 & 100 & 8 \\
\hline L0M100_4 & 0 & 100 & 4 \\
\hline L25M75_12 & 25 & 75 & 12 \\
\hline L25M75_8 & 25 & 75 & 8 \\
\hline L25M75_4 & 25 & 75 & 4 \\
\hline L50M50_12 & 50 & 50 & 12 \\
\hline L50M50_8 & 50 & 50 & 8 \\
\hline L50M50_4 & 50 & 50 & 4 \\
\hline L75M25_12 & 75 & 25 & 12 \\
\hline L75M25_8 & 75 & 25 & 8 \\
\hline L75M25_4 & 75 & 25 & 4 \\
\hline L100M0_12 & 100 & 0 & 12 \\
\hline L100M0_8 & 100 & 0 & 8 \\
\hline L100M0_4 & 100 & 0 & 4 \\
\hline
\end{tabular}


Table 3 - Geometry of wall specimens tested in previous research works.

\begin{tabular}{|c|c|c|c|c|}
\hline \multirow[b]{2}{*}{ Reference } & \multirow{2}{*}{$\begin{array}{c}\text { Dimensions of the } \\
\text { walls } \\
\mathrm{L} \times \mathrm{W} \times \mathrm{H}\left(\mathrm{mm}^{3}\right)\end{array}$} & \multicolumn{2}{|c|}{ Thickness of the leaves (mm) } & \multirow{2}{*}{$w_{i} / 2 w$} \\
\hline & & $\begin{array}{c}\text { External } \\
w_{\mathrm{e}}\end{array}$ & $\begin{array}{c}\text { Core } \\
w_{\mathrm{i}}\end{array}$ & \\
\hline Vintezileou and Tassios (1995) & $600 \times 400 \times 1200$ & 130 & 140 & 0.54 \\
\hline Toumbakari (2002) & $600 \times 400 \times 1200$ & 90 & 220 & 1.22 \\
\hline Valluzzi et al. (2004) & $800 \times 500 \times 1400$ & 180 & 140 & 0.39 \\
\hline
\end{tabular}


Table 4 - Compressive strength of the specimens of the leaves (the coefficient of variation is indicated inside parentheses).

\begin{tabular}{ccc}
\hline Specimens & $\begin{array}{c}\text { Average compressive strength } \\
\left(\mathrm{N} / \mathrm{mm}^{2}\right)\end{array}$ & $\begin{array}{c}\text { Normalized } \\
\text { compressive strength }^{*}(-)\end{array}$ \\
\hline Inner leaf & $0.3(45 \%)$ & 1.0 \\
Outer leaf & $9.2(19 \%)$ & 30.7 \\
Injected inner leaf & $4.1(12 \%)$ & 13.6 \\
\hline * Using the inner leaf compression value for normalization
\end{tabular}

* Using the inner leaf compression value for normalization 
Table 5 - Summary of results of the unstrengthened walls.

\begin{tabular}{cccccc}
\hline Wall & $f_{c, W}\left(\mathrm{~N} / \mathrm{mm}^{2}\right)$ & $\mathcal{E}_{v, p}(\mathrm{~mm} / \mathrm{m})$ & $\mathcal{E}_{h, p}(\mathrm{~mm} / \mathrm{m})$ & $E_{0}\left(\mathrm{~N} / \mathrm{mm}^{2}\right)$ & $E_{30-60}\left(\mathrm{~N} / \mathrm{mm}^{2}\right)$ \\
\hline $1 \mathrm{~W} 1$ & 2.3 & 6.81 & 3.52 & 3246 & 780 \\
$1 \mathrm{~W} 2$ & 1.7 & 2.86 & 4.10 & 2087 & 1889 \\
$2 \mathrm{~W} 1$ & 1.4 & 9.37 & 2.69 & 1422 & 711 \\
$3 \mathrm{~W} 1$ & 2.6 & 3.87 & 7.85 & 1733 & 1351 \\
\hline Average & 2.0 & 5.73 & 4.54 & 2122 & 1183 \\
CoV $(\%)$ & 27 & 51 & 50 & 38 & 47 \\
\hline
\end{tabular}


Table 6 - Summary of results of the walls strengthened by transversal tying.

\begin{tabular}{cccccc}
\hline Wall & $f_{c, W}\left(\mathrm{~N} / \mathrm{mm}^{2}\right)$ & $\varepsilon_{v, p}(\mathrm{~mm} / \mathrm{m})$ & $\varepsilon_{h, p}(\mathrm{~mm} / \mathrm{m})$ & $E_{0}\left(\mathrm{~N} / \mathrm{mm}^{2}\right)$ & $E_{30-60}\left(\mathrm{~N} / \mathrm{mm}^{2}\right)$ \\
\hline $2 \mathrm{~W} 2$ & 3.3 & 9.35 & 11.05 & 1954 & 722 \\
$2 \mathrm{~W} 3$ & 2.6 & 5.93 & 2.97 & 1707 & 603 \\
$2 \mathrm{~W} 4$ & 3.5 & 9.37 & $8.26 *$ & 1160 & 675 \\
\hline Average & 3.1 & 8.21 & $7.01 * *$ & 1607 & 667 \\
CoV (\%) & 27 & 51 & $81^{* *}$ & 25 & 9 \\
* value corresponding to $99 \%$ of $f_{c, W}$ since it became not possible to take measurements till peak load \\
** does not include the wall $2 \mathrm{~W} 4$
\end{tabular}


Table 7 - Summary of results of the walls strengthened by grout injection.

\begin{tabular}{cccccc}
\hline Wall & $f_{c, W}\left(\mathrm{~N} / \mathrm{mm}^{2}\right)$ & $\varepsilon_{v, p}(\mathrm{~mm} / \mathrm{m})$ & $\varepsilon_{h, p}(\mathrm{~mm} / \mathrm{m})$ & $E_{0}\left(\mathrm{~N} / \mathrm{mm}^{2}\right)$ & $E_{30-60}\left(\mathrm{~N} / \mathrm{mm}^{2}\right)$ \\
\hline $3 \mathrm{~W} 2$ & 3.9 & 7.00 & 4.74 & 2172 & 1604 \\
$3 \mathrm{~W} 3$ & 3.3 & 6.87 & 3.77 & 1844 & 114 \\
\hline Average & 3.6 & 6.93 & 4.26 & 2008 & 1359 \\
CoV $(\%)$ & 11 & 1 & 16 & 12 & 26 \\
\hline
\end{tabular}


Table 8 - Summary of results of the wall strengthened by combination of transversal tying and grout injection.

\begin{tabular}{cccccc}
\hline Wall & $f_{c, W}\left(\mathrm{~N} / \mathrm{mm}^{2}\right)$ & $\varepsilon_{v p}(\mathrm{~mm} / \mathrm{m})$ & $\varepsilon_{h, p}(\mathrm{~mm} / \mathrm{m})$ & $E_{0}\left(\mathrm{~N} / \mathrm{mm}^{2}\right)$ & $E_{30-60}\left(\mathrm{~N} / \mathrm{mm}^{2}\right)$ \\
\hline $3 \mathrm{~W} 4$ & 3.8 & 4.86 & 1.43 & 3539 & 1849 \\
\hline
\end{tabular}




\section{LIST OF FIGURES CAPTIONS}

Fig. 1 - Compressive strength of the mortars tested in the composition study: (a) L0M100; (b) L25M75; (c) L50M50; (d) L75M25; (e) L100M0.

Fig. 2 - Construction of the walls: (a) geometry; (b) execution of the external leaves; (c) execution of the core.

Fig. 3 - Specimens from the leaves: (a) external; (b) core; (c) injected core.

Fig. 4 - Strengthening by transversal tying: (a) distribution of the tyings; (b) sealing of a tying; (c) injection.

Fig. 5 - Strengthening by grout injection: (a) disposition of the tubes; (b) sealing of the transversal faces; (c) pressure pot.

Fig. 6 - Test setup of the walls: (a) testing machine; (b) location of the displacement transducers.

Fig. 7 - Compressive stress - strain curves of the unstrengthened walls.

Fig. 8 - Evolution of the $\square$ parameter with regard to the compressive stress for the unstrengthened walls.

Fig. 9 - Crack pattern of the unstrengthened wall 3W1.

Fig. 10 - Compressive stress - strain curves of the walls strengthened by transversal tying.

Fig. 11 - Evolution of the $\square$ parameter with regard to the compressive stress for the walls strengthened by transversal tying.

Fig. 12 - Crack pattern of wall 2W4.

Fig. 13 - Compressive stress - strain curves of the walls strengthened by grout injection.

Fig. 14 - Evolution of the $\square$ parameter with regard to the compressive stress for the walls strengthened by grout injection.

Fig. 15 - Crack pattern of wall 3W3.

Fig. 16 - Compressive stress - strain curve of wall 3W4.

Fig. 17 - Evolution of the $\square$ parameter with regard to the compressive stress for the wall 3W4.

Fig. 18 - Crack pattern of wall 3W4. 


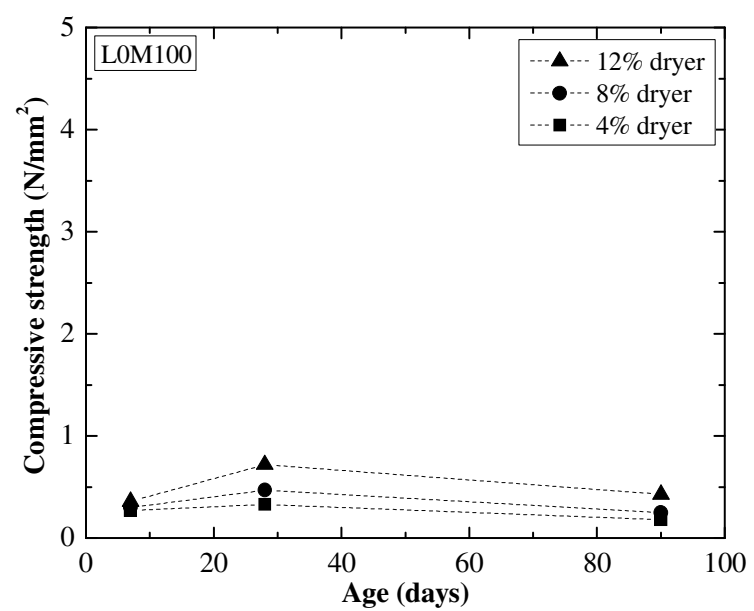

(a)

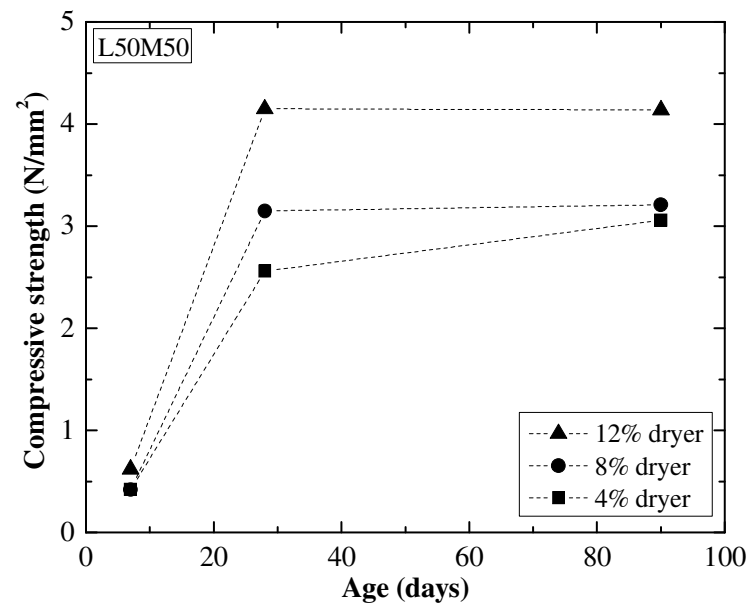

(c)

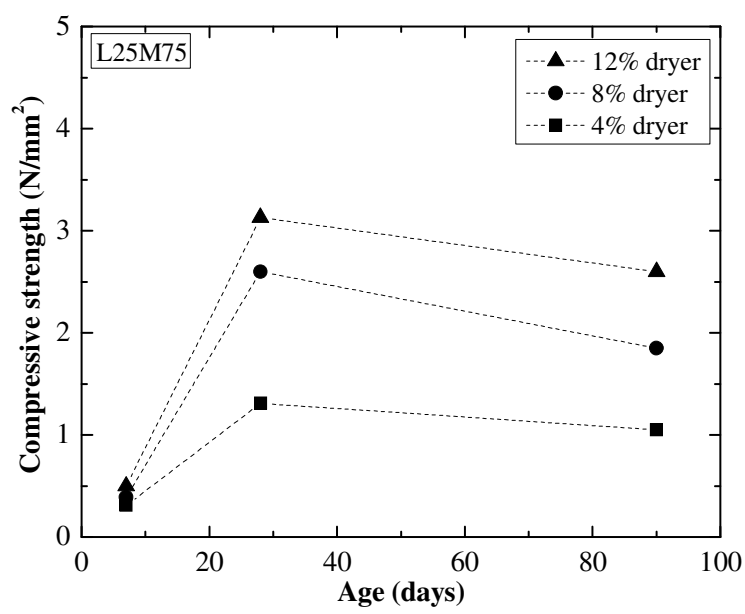

(b)

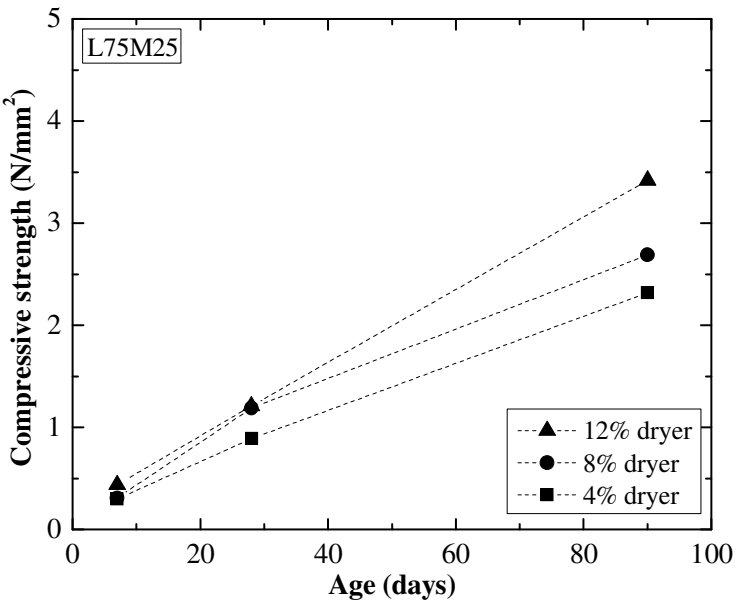

(d)

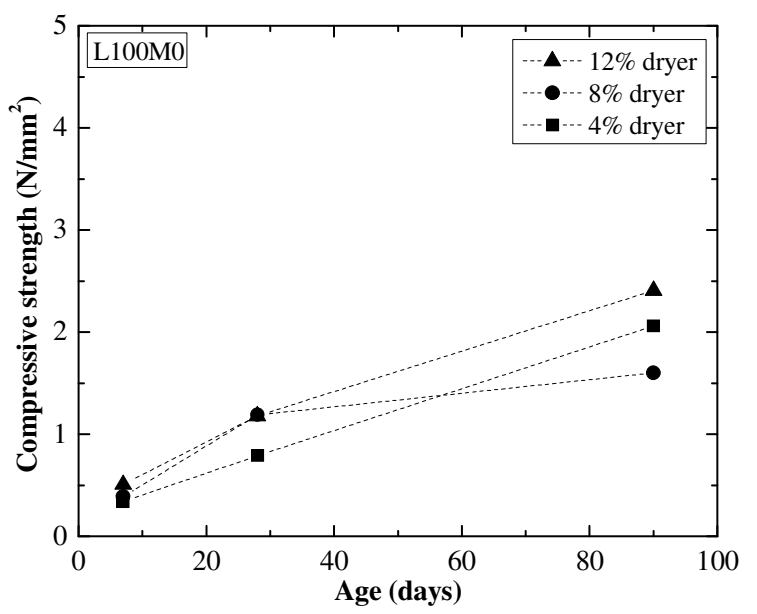

(e)

Fig. 1 - Compressive strength of the mortars tested in the composition study: (a) L0M100; (b) L25M75;

(c) L50M50; (d) L75M25; (e) L100M0. 


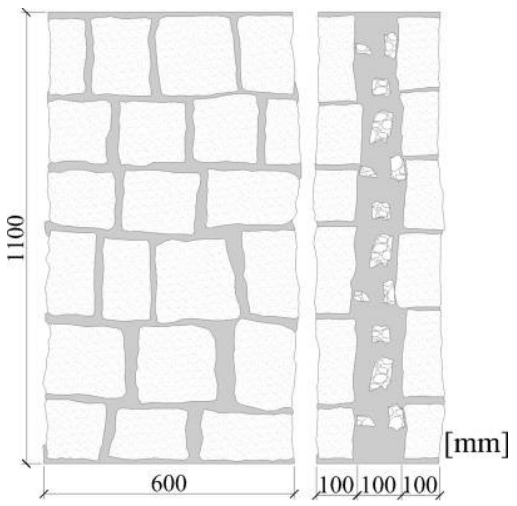

(a)

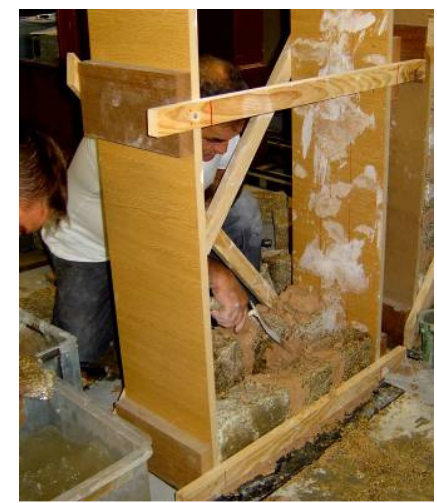

(b)

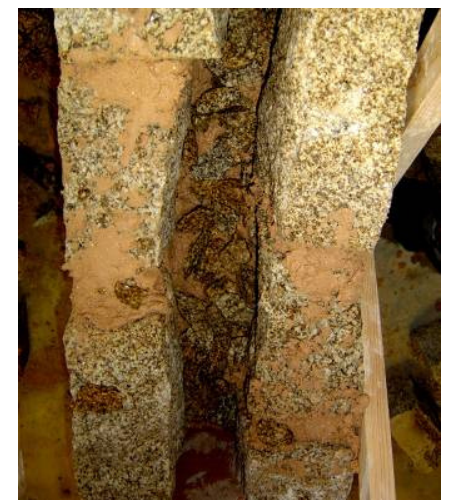

(c)

Fig. 2 - Construction of the walls: (a) geometry; (b) execution of the external leaves; (c) execution of the core. 


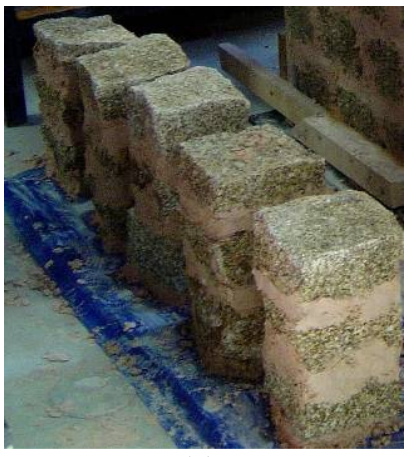

(a)

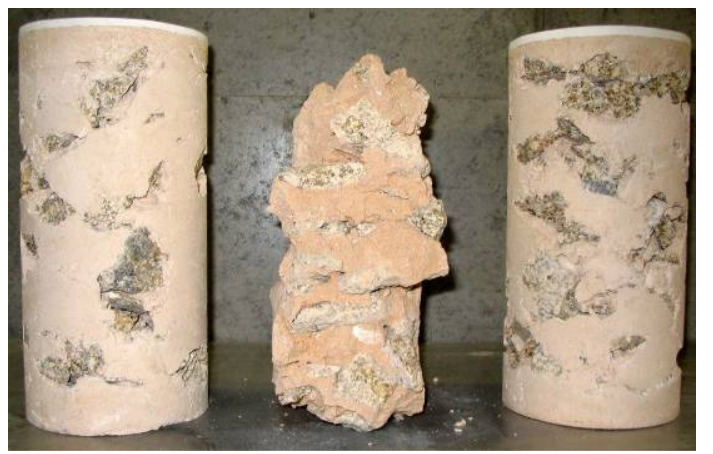

(b)

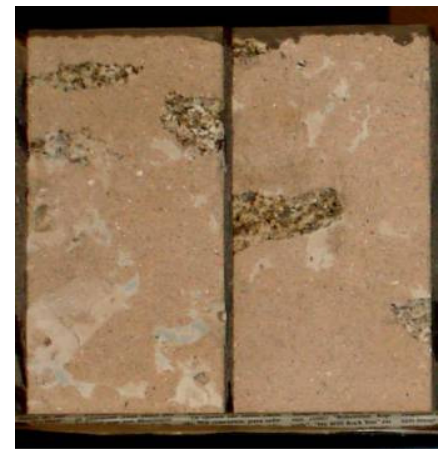

(c)

Fig. 3 - Specimens from the leaves: (a) external; (b) core; (c) injected core. 


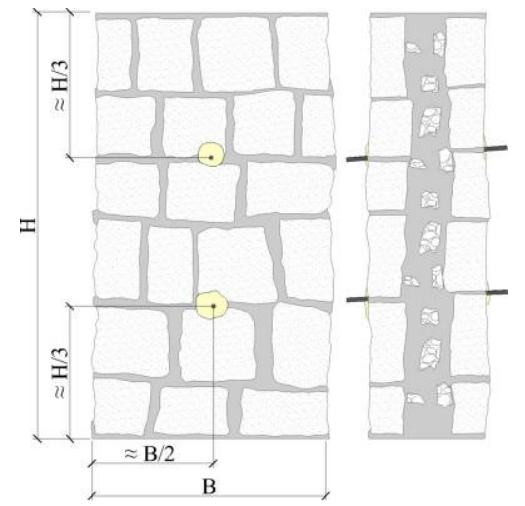

(a)

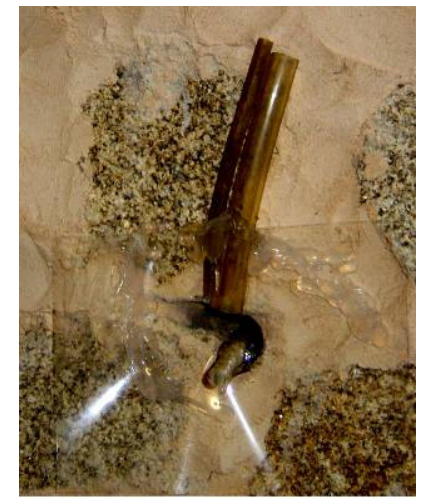

(b)

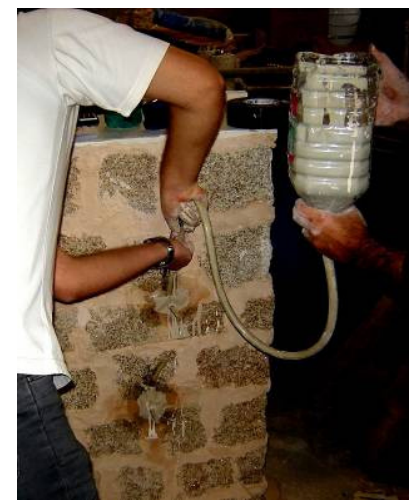

(c)

Fig. 4 - Strengthening by transversal tying: (a) distribution of the ties; (b) sealing of a tying; (c) injection. 


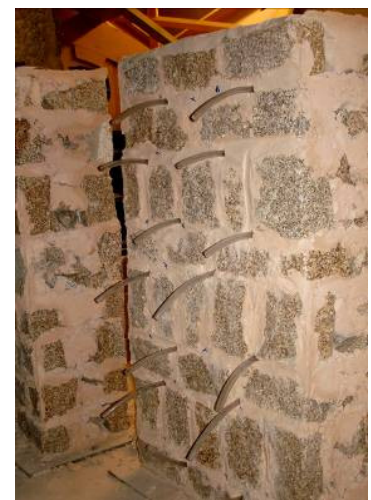

(a)

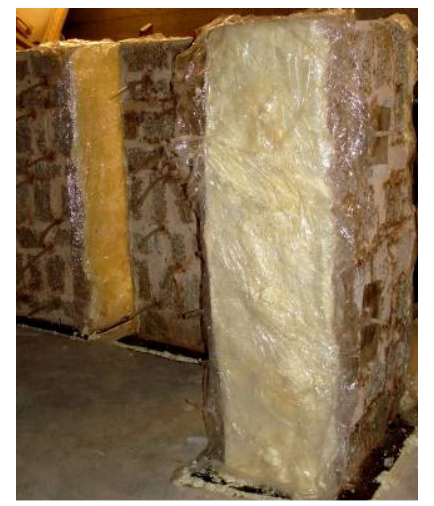

(b)

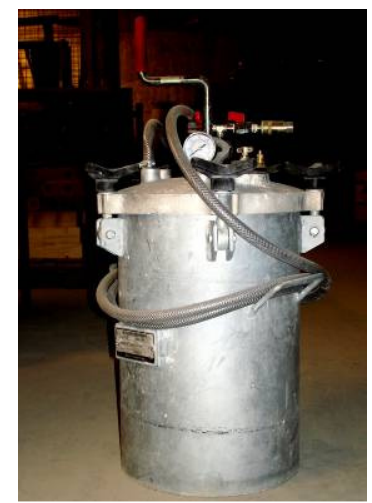

(c)

Fig. 5 - Strengthening by grout injection: (a) disposition of the tubes; (b) sealing of the transversal faces; (c) pressure pot. 


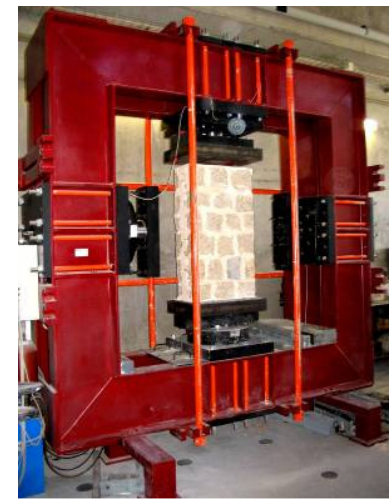

(a)

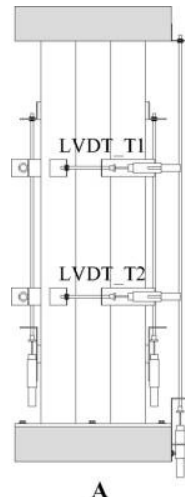

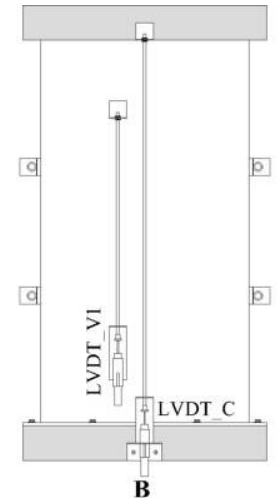

B

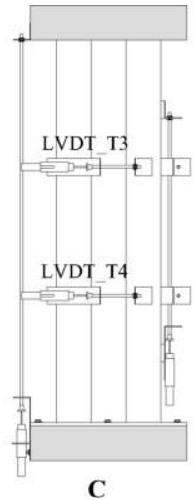

(b)

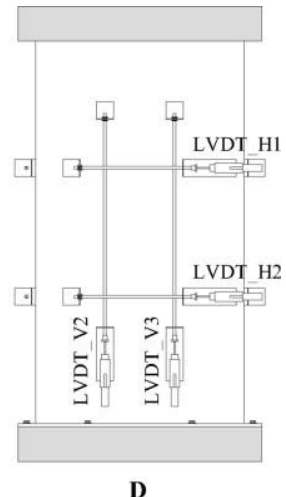

D

Fig. 6 - Test setup of the walls: (a) testing machine; (b) location of the displacement transducers. 


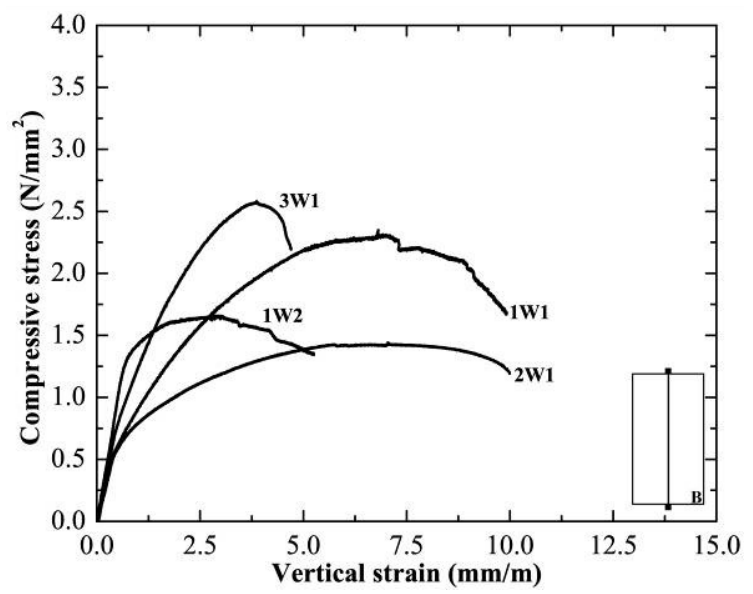

Fig. 7 - Compressive stress - strain curves of the unstrengthened walls. 


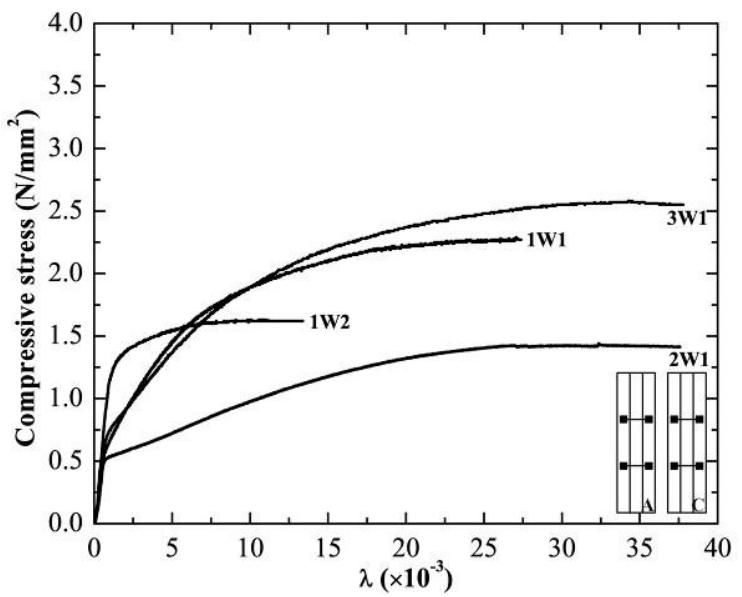

Fig. 8 - Evolution of the $\lambda$ parameter with regard to the compressive stress for the unstrengthened walls. 

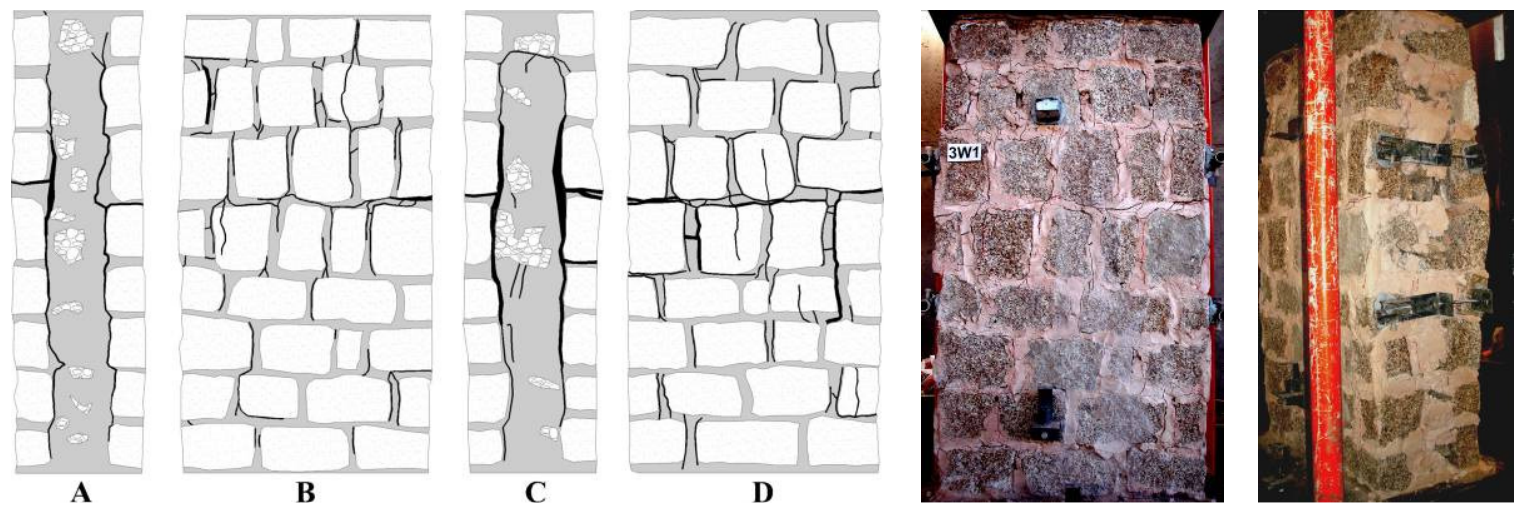

Fig. 9 - Crack pattern of the unstrengthened wall 3W1. 


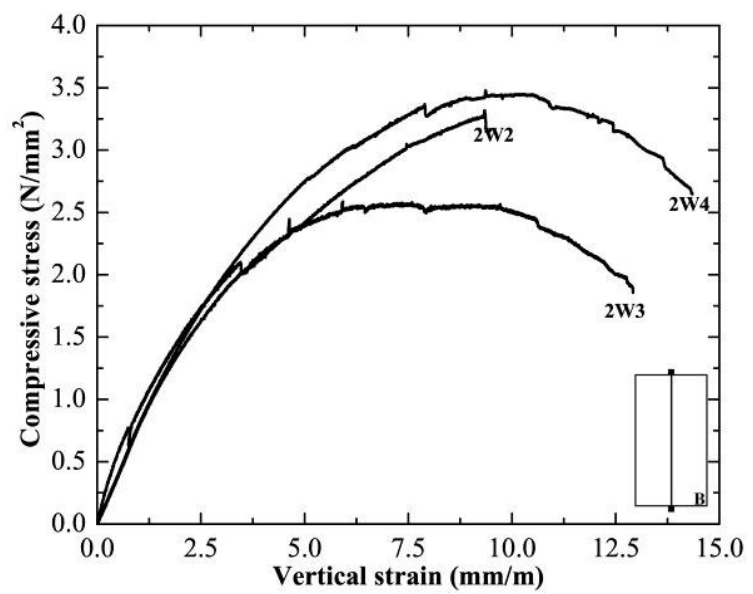

Fig. 10 - Compressive stress - strain curves of the walls strengthened by transversal tying. 


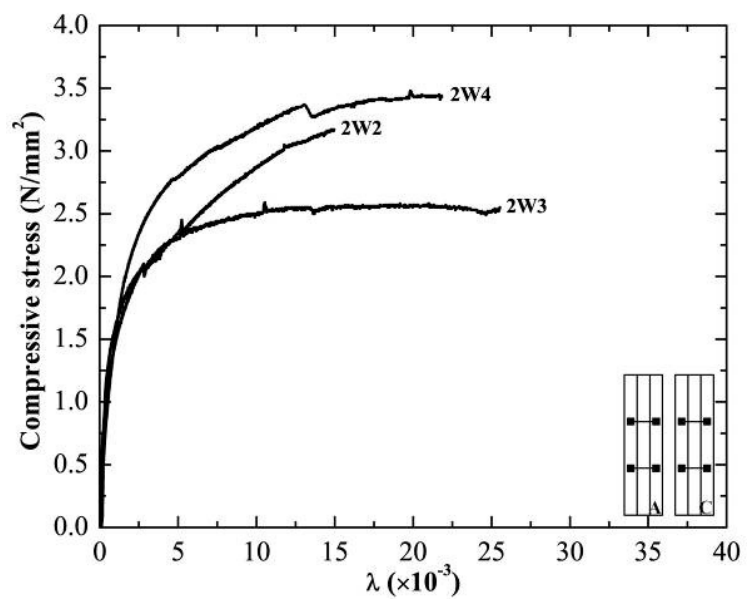

Fig. 11 - Evolution of the $\lambda$ parameter with regard to the compressive stress for the walls strengthened by transversal tying. 

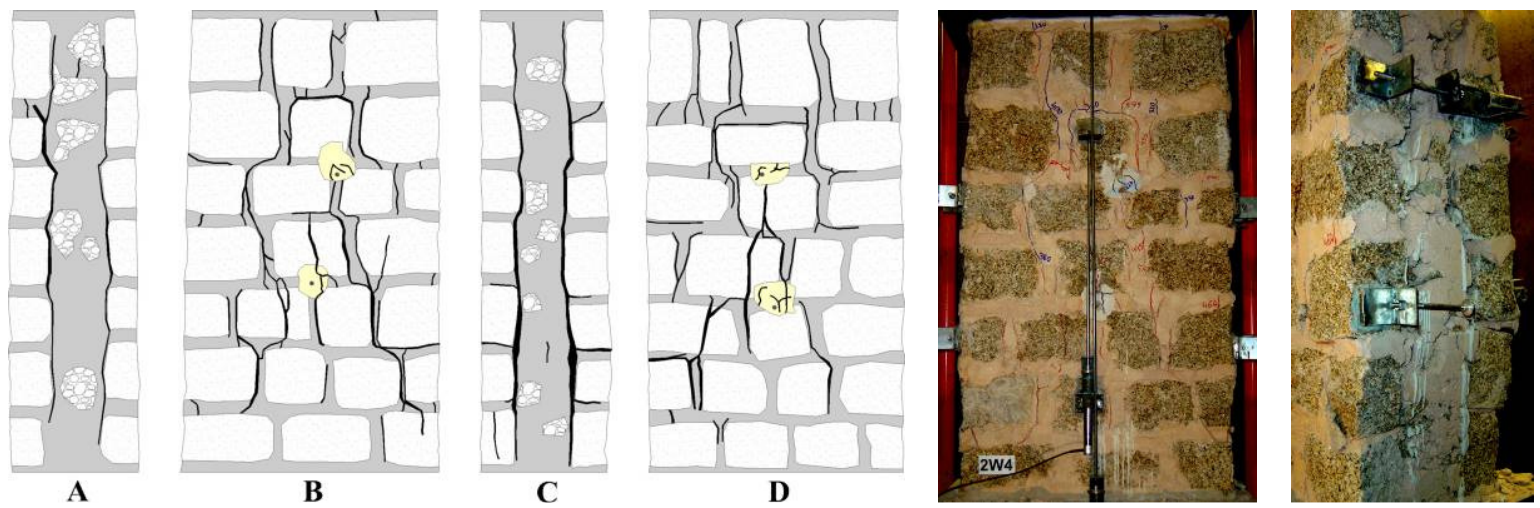

Fig. 12 - Crack pattern of wall $2 \mathrm{~W} 4$. 


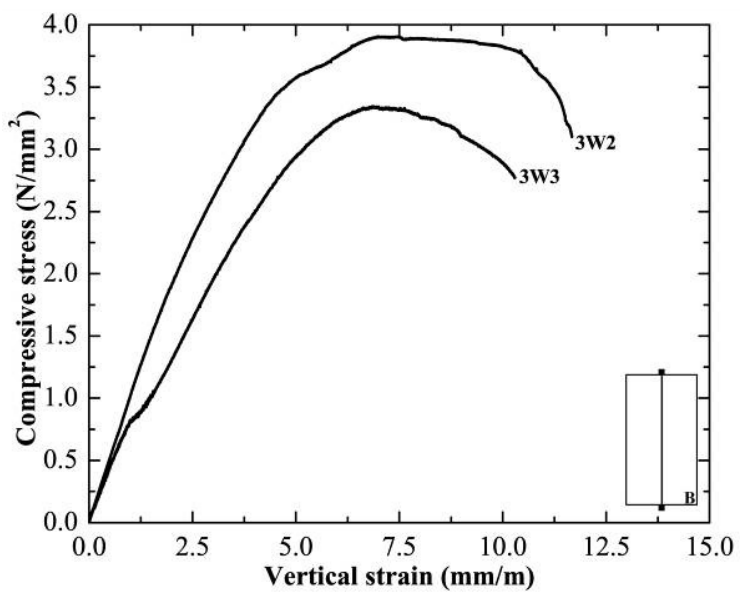

Fig. 13 - Compressive stress - strain curves of the walls strengthened by grout injection. 


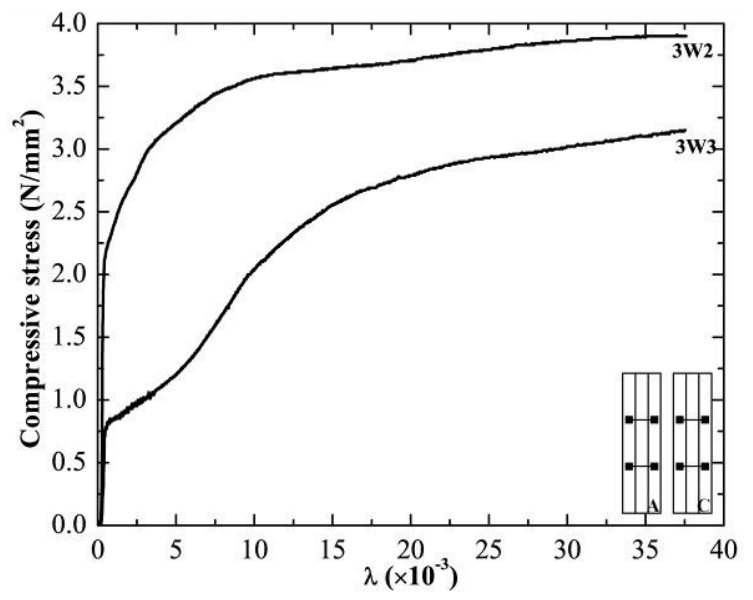

Fig. 14 - Evolution of the $\lambda$ parameter with regard to the compressive stress for the walls strengthened by grout injection. 

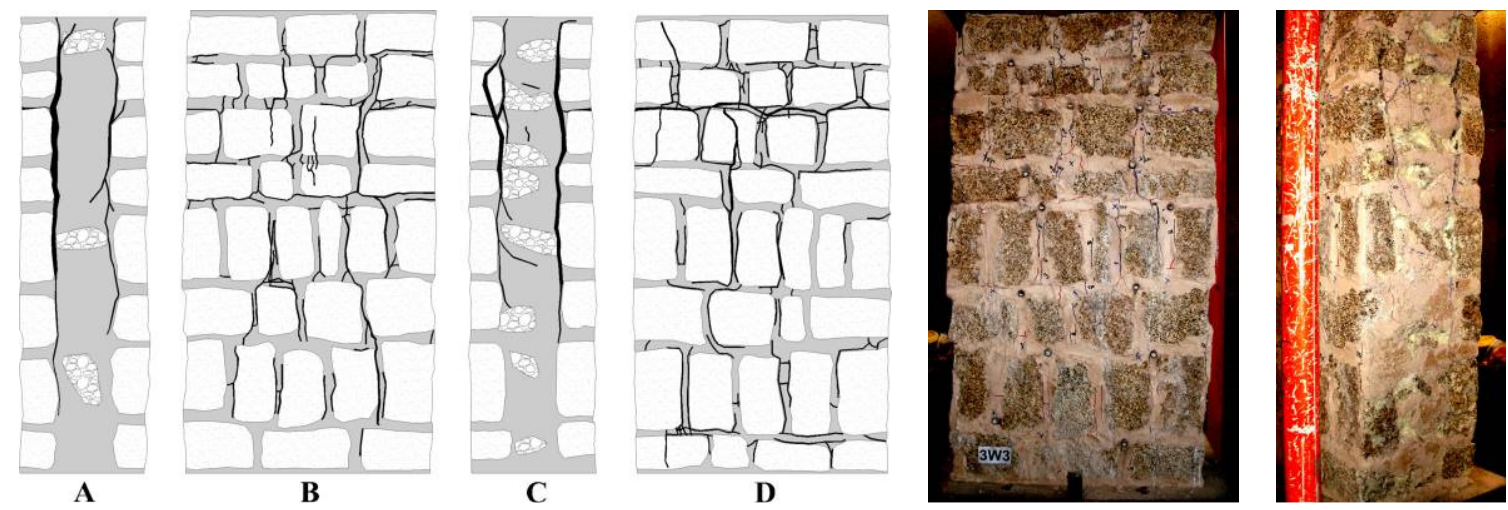

Fig. 15 - Crack pattern of wall 3W3. 


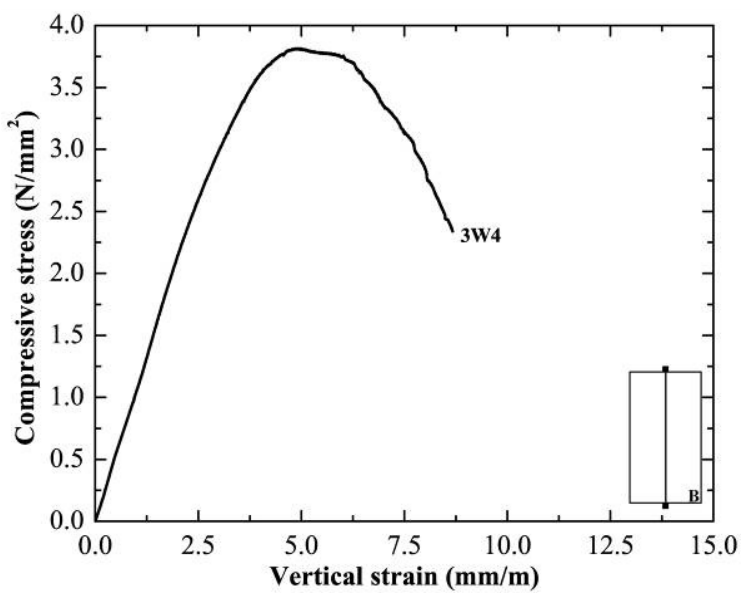

Fig. 16 - Compressive stress - strain curve of wall 3W4. 


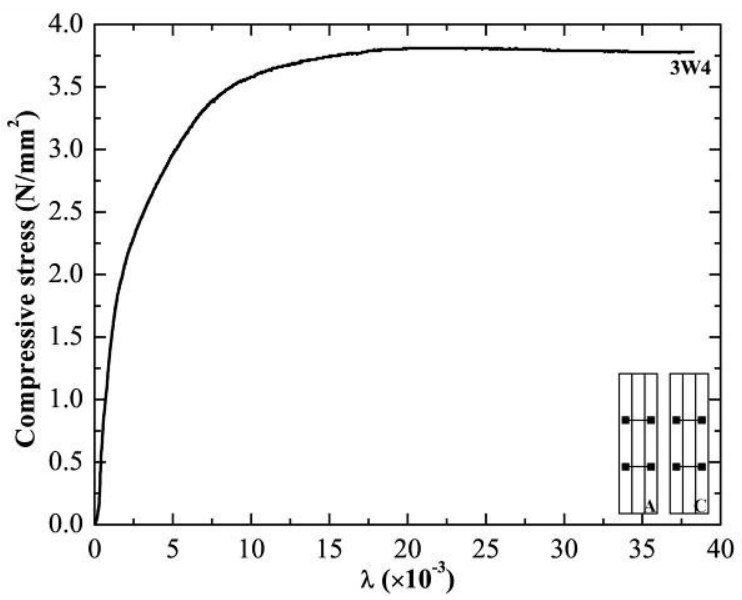

Fig. 17 - Evolution of the $\lambda$ parameter with regard to the compressive stress for the wall $3 \mathrm{~W} 4$. 
ERROR: stackunderflow OFFENDING COMMAND:

STACK : 